\title{
Pneumothorax during Cardiomyotomy: Management
}

\author{
Sonia Nayak
}

\begin{abstract}
Laparoscopic cardiomyotomy is the surgical mode of treatment for patients suffering from achalasia cardia. These patients are at a risk of developing intraoperative pneumothorax with hemodynamic and respiratory changes. We reported case of pneumothorax during laparoscopic cardiomyotomy. Patient developed hypotension, tachycardia, decreased air entry and increased peak airway pressure. We managed that case successfully. Hemodynamics was maintained with fluid and ephedrine. Patient was ventilated with $100 \%$ Oxygen and put on pressure cycled ventilator mode. Postoperatively patient was observed in ICU. While managing such cases, anesthetists should be aware of this complication and be vigilant.
\end{abstract}

Keywords: Achalasia cardia, Laparoscopic cardiomyotomy, Pneumothorax.

How to cite this article: Nayak S. Pneumothorax during Cardiomyotomy: Management. Res Inno in Anesth 2016;1(2): 71-72.

\section{Source of support: Nil}

Conflict of interest: None

\section{INTRODUCTION}

Patients undergoing cardiomyotomy are at a risk and of developing intraoperative pneumothorax with hemodynamic changes and changes in respiratory parameters. Anesthetists should be aware of this complication and be vigilant.

\section{CASE REPORT}

A 76-year-old female patient was presented for cardiomyotomy. The patient was diabetic, hypertensive, and well controlled by oral medications. The patient was of short stature and her weight was $36 \mathrm{~kg}$.

The patient's investigations including two-dimensional echocardiography reports were within normal limits.

On examination, vitals were within normal limits.

The patient was given premedication, i.e., injection glcopyrollate $4 \mu \mathrm{g} / \mathrm{kg}$, injection midazolam $0.03 \mathrm{mg} / \mathrm{kg}$, and injection fentanyl $2 \mu \mathrm{g} / \mathrm{kg}$. The patient was induced

\section{Consultant}

Department of Anesthesiology, Jeevanshree Hospital, Dombivali Maharashtra, India

Corresponding Author: Sonia Nayak, Consultant, Department of Anesthesiology, Jeevanshree Hospital, Dombivali, Maharashtra, India, Phone: +919930480526, e-mail: nayaksonia@gmail.com with injection propofol $80 \mathrm{mg}$ and injection scoline $75 \mathrm{mg}$. She was intubated with 7 number cuffed endotracheal tube. She was maintained on oxygen, nitrous oxide, sevoflurane, and injection vecuronium. The patient was ventilated with a closed circuit and kept on controlled ventilation mode.

Vitals, i.e., pulse, blood pressure, electrocardiogram, peripheral capillary oxygen $\left(\mathrm{SpO}_{2}\right)$ were monitored.

Intraoperative, there was a pleural tear (patient's pleura was very thin and fragile).

The patient had sudden hypotension and sudden tachycardia. Her peak airway pressures rose suddenly. On inspection, there was reduced expansion of left side of chest. On auscultation, there was reduced air entry on the left side. Intraoperative, there was a pleural tear as patient's pleura was very thin and fragile.

The patient was given 100\% oxygen (nitrous oxide was switched off immediately).

Fluids were given and injection ephedrine was given.

Patient was immediately shifted to pressure-cycled ventilation on the anesthesia machine ventilator, with peak pressure set at $25 \mathrm{~mm} \mathrm{Hg}$.

The patient was observed for half an hour.

Since the blood pressure came back to normal, tachycardia settled, etCO $\mathrm{CO}_{2}$ remained at the upper limits of normal range (around 44-46 $\mathrm{mm} \mathrm{Hg}$ ), and the $\mathrm{SpO}_{2}$ stayed above $96 \%$ on $100 \% \mathrm{O}_{2}$, the surgery was continued.

The pleura was sutured and cardiomyotomy with anterior fundoplication performed.

There was dilemma regarding insertion of intercostal drain.

Post release of pneumoperitoneum, patient was hyperventilated on pressure cycled mode and etCO $\mathrm{O}_{2}$ was got to normal range between 35 and $40 \mathrm{~mm} \mathrm{Hg}$.

Intercostal tube placement was differed with readiness to inset it post extubation if required.

Once patient was fully awake patient was reversed and extubated.

The patient was put on $\mathrm{O}_{2}$ with mask and observed in recovery room for 2 hours. The postoperative patient's air entry was mildly reduced but patient did not have any tachycpnea or tachycardia. The patient's blood pressure was maintained, and saturation on oxygen at $6 \mathrm{~L} /$ minute was maintained at around 97 and 98\%. Postoperatively, immediately a chest $X$-ray was done which showed mild pneumothorax on left side. The patient was observed in intensive care unit (ICU) for 1 day postoperative with 
oxygen continued. An X-ray was repeated on day 2 postoperative which was normal. On auscultation, bilateral air entry was normal.

The patient was discharged on day 3 .

\section{DISCUSSION}

Cardiomyotomy (anterior or posterior) is the surgical mode of treatment for patients suffering from achalasia cardia. ${ }^{1}$ Laparoscopic cardiomyotomy was described in 1991 by Cuschieri et al. ${ }^{2}$ An antireflux procedure like anterior fundoplication (dor) or posterior fundoplication (toupe) is to be done in conjunction with cardiomyotomy. ${ }^{3,4}$

About $5 \%$ of patients' chest $X$-ray show mild pneumothorax, which rarely need treatment as the $\mathrm{CO}_{2}$ is rapidly absorbed.

But sometimes pneumothorax during laparoscopic surgery can be a potentially life-threatening complication. It aggravates physiological effects of intraperitoneal carbon dioxide insufflation. It causes cardiorespiratory changes particularly in elderly patients with co-morbidities. ${ }^{5}$ Appropriate monitoring and a high index of suspicion can result in early diagnosis and treatment of such a complication. The management of pneumothorax depends on the stage of surgery and cardiorespiratory parameters of the patient.

In case of signs, such as sudden hypotension, sudden tachycardia, sudden desaturation, sudden increase in peak inspiratory pressures, and a rise in $\mathrm{CO}_{2}$, an intraoperative pneumothorax should be suspected. ${ }^{6}$ Patient should be given $100 \% \mathrm{O}_{2}\left(\mathrm{~N}_{2} \mathrm{O}\right.$ should be avoided), vasopressors, fluids, and hyperventilation with pressurecycled ventilation should be continued. An intercostal chest tube may have to be placed. ${ }^{7}$

A postoperative chest X-ray is a must. Any signs of postoperative tachycpnea, tachycardia, and fall in saturation should be treated immediately, and sometimes a postoperative ICD (implantable cardiac defibrillator) may have to be placed.
The incidences of postoperative continuation of ventilatory support and ICD insertion are less than 5\% as the $\mathrm{CO}_{2}$ get absorbed rapidly.

If detected toward the end of the procedure in a stable patient, the operation should be completed and nothing further needs to be done, as the carbon dioxide in the pleural cavity gets reabsorbed rapidly after deflating the abdomen. ${ }^{7}$

In any case, serial X-rays may be required and the patient should be observed. Serial arterial blood gas may be required.

\section{CONCLUSION}

This case report is to highlight the occurrence of pneumothorax intraoperative during cardiomyotomy procedure and to highlight the intraoperative as well as postoperative care and in such patients.

\section{REFERENCES}

1. Andreollo NA, Earlam RJ. Heller's myotomy for achalasia: is an added anti-reflux procedure necessary? Br J Surg 1987 Sep;74(9):765-769.

2. Shimi S, Nathanson LK, Cushieri A. Laparoscopic cardiomyotomy for achalasia. J R Coll Surg Edinb 1991;36:152-154.

3. Heniford BT, Matthews BD, Kercher KW, Yavorski R, Greer SF, Goldstein SL, Deal SE, Paccico T, Drake S, Colvin A, et al. Laparoscopic anterior esophageal myotomy and Toupet fundoplication for achalasia. Am Surg 2001 Nov;67(11): 1059-1065.

4. Schulz HG, Loick J, Hessling M, Hohlbach G. Laparoscopic Heller cardiomyotomy either combined with a Dor or Toupet procedure in the treatment of achalasia. Zentralbl Chir 2004 Oct;129(5):381-386.

5. Leonard IE, Cunningham AJ. Anaesthetic considerations for laparoscopic cholecystectomy. Best Pract Res Clin Anaesthesiol 2002;16:1-20.

6. Togal T, Gulhas N, Cicek M, Teksan H, Ersoy O. Carbon dioxide pneumothorax during laparoscopic surgery. Surg Endosc 2002;16:1242-1244.

7. Kumar LCG, Singh MAK. Pneumothorax during Laparoscopic Cholecystectomy. MJAFI 2007;63:277-278. 